\title{
REFLEXÕES SOBRE A MEMÓRIA BIOGRÁFICA NO MEIO AUDIOVISUAL CONTEMPORÂNEO
}

\author{
Marcio Markendorf \\ Universidade Federal de Santa Catarina
}

\begin{abstract}
Resumo: O relato biográfico tradicional segue um modelo positivista, centrado em relações de causa e efeito, e compõe um percurso cronológico para apresentar a lógica de uma história de vida. Nas últimas décadas, estudiosos questionaram essa forma cristalizada e propuseram novas possibilidades para o discurso biográfico. O produto audiovisual, objeto de interesse deste trabalho, apesar de apresentar certas vantagens em relação ao modelo de papel, segue produzindo roteiros nos quais as fatias de vida de um sujeito são uma sucessão ordenada de acontecimentos no tempo. O objetivo do texto é, portanto, refletir sobre como a memória biográfica está presente no cinema e quais modificações são introduzidas no modelo trivial pela contemporaneidade, de modo a remover o aspecto mítico que envolve os biografados.

Palavras-chave: Biografia. Cinebiografia. Contemporaneidade. Memória. Representação.
\end{abstract}

\section{Enquadrando a cinebiografia}

Em linhas gerais pode-se dizer que a pós-modernidade é um momento marcado pela relativização dos saberes, condição que leva à desconstrução das certezas e ao desmoronamento dos discursos autoritários. A palavra autoridade, nesse contexto, deve ser tomada em seu sentido de força convincente, fundamento e base - elementos responsáveis por imbuir os objetos da qualidade necessária para se tornarem mais que verossímeis, isto é, para que assumam uma expressão (amplamente aceita com) autêntica da realidade. Para alguns

\section{(1) 9}

Esta obra está licenciada sob uma Licença Creative Commons.

\footnotetext{
* Possui graduação em Letras Português/Inglês pela Universidade Federal de Mato Grosso do Sul (2003) e fez doutorado direto em Literatura, concentração em Teoria da Literatura, pela Universidade Federal de Santa Catarina (2009). Atualmente é Professor Adjunto do Departamento de Artes e Libras da Universidade Federal de Santa Catarina e leciona no Curso de Cinema. É membro do Conselho Científico da Revista Anuário de Literatura, publicação do Programa de Pós-graduação em Literatura da UFSC, e da Revista Rascunhos Culturais, publicação do curso de Letras da UFMS, CPX. Está vinculado aos Grupos de Pesquisa Literatura e Memória e Arte e Mestiçagens poéticas. Tem experiência na área de Letras e Cinema, com ênfase em Teoria da Literatura, atuando e publicando sobre os seguintes temas: ficção, representação, (cine)biografia, memória, imaginário.
} 
teóricos pós-modernos, alinhados sob o axioma nietzschiano do "Deus está morto", estamos diante de um momento de perda dos fundamentos filosóficos, no qual o principal conflito dáse não pela falta de realidade, mas pela multiplicidade de realidades possíveis, condição que assume igualmente a verdade e a mentira como uma ficção.

Nesse cenário, contribuindo para relativizar as noções tradicionais de representação, de verdade e de identidade das histórias de vida, Pierre Bourdieu ressaltou certo caráter provisório e niilista da pós-modernidade em seu ensaio "A ilusão biográfica". Como parte do repertório cultural da civilização, parafraseando o sociólogo francês (BOURDIEU, 2006, p. 184), o gênero biográfico tal como é conhecido encontra uma forma aceitável de expressão de uma complexa trajetória de vida por meio de uma ilusão discursiva - a cronologia dos fatos e o sentido de vida extraído dela - para o qual, podemos acrescentar, cria-se uma espécie de força que atua no sentido de construir a pessoa biografada como um tipo de personagem. A verdade e a mentira, portanto, como termos binários de oposição, convivem no mesmo espaço, e ambas procuram autorizar-se na leitura como propriedade discursiva autêntica.

O discurso biográfico legitimado até então, segundo a análise de Bourdieu (2006, p. 184), por ser estruturado em sequências lógicas, inteligíveis e cronológicas, adere ao "postulado do sentido da existência" por meio do qual o relato se torna razoável, consistente, constante e estruturado com base em relações causais. O emprego desses procedimentos permitiria a construção artificial de sentido para uma trajetória de vida, pois, em função de uma intenção discursiva particular, o biógrafo do papel seleciona certos acontecimentos que considera significativos e estabelece conexões coerentes entre eles. O mesmo ocorre com o memorialista do cinema, um dos objetos culturais do qual este artigo pretende tratar, pois, como afirma o roteirista Syd Field (2001, p. 181), os "roteiros que lidam com pessoas, vivas ou mortas - biografias audiovisuais - têm que ser seletivos e concentrados para serem eficientes". Eficiência e coerência, portanto, refletem a dramatúrgica noção de unidade narrativa.

Esse recorte inteligível é justificável: a vida de um sujeito é formada por um sem número de acontecimentos insignificantes, triviais e cotidianos, e de outros poucos acontecimentos realmente significativos (sem cogitar a hipótese psicanalítica da memória afetiva como uma espécie de ficção). Assim, por ser caótica e imprevisível, a multiplicidade de eventos na vida de um sujeito é completamente oposta ao sentido uno e coerente assumido pela estrutura dos relatos de vida. É mais provável que a liberdade de sermos coerentes e incoerentes, em diferentes graus de alternância, seja para nós mais uma fonte de prazer que de 
culpa, visto que a constância das ações e do caráter pode produzir monotonia. No entanto, o que vale para a experiência visceral não vale para a discursiva. Por isso, um dos motivos para que a ilusão poética das coisas seja desejável é que, por intermédio das narrativas, ao perceber a vida de forma explicável, o leitor/espectador atravessa seguro pelo vazio dos acontecimentos e pela indeterminação do mundo, uma vez que tudo pode ser disposto em uma estrutura ordenada.

O sujeito biografado na modernidade era um modelo de comportamento para o público porque seria possível, por meio dessa espécie narrativa, aprender com os conflitos e as oportunidades do outro. Por essa razão, as tradicionais narrativas de vida funcionaram por muito tempo como instrumento de edificação humana ao tratar do sujeito bem-sucedido. A essência do sucesso, entretanto, só poderia ser extraída com o fim de uma trajetória de vida, motivo pelo qual o relato biográfico até pouco tempo era considerado um gênero dos mortos.

$\mathrm{O}$ encontro com o absoluto, simbolizado pela morte e pelo registro histórico que tornará alguém imortal, constituía a essência do herói biografado até o início do século XX. O meio audiovisual, por exemplo, contribuiu para uma série de transformações no modo de representar os sujeitos e de apresentar suas vidas. No cinema americano, por exemplo, durante o auge do star system, nas décadas de 1910 até 1940 produziram-se, por meio das "estrelas", fictícias histórias biográficas que figuravam como uma promessa messiânica de felicidade. De modo nada ingênuo, o star system fundira a personalidade das personagens à dos atores que as encarnavam na tela, de modo a instaurar a indistinção entre a ficção e a vida real, isto é, de criar a falsa ideia de "unidade de identidade". Era como se os produtores procurassem decididamente apostar na fantasia da "vida como sonho" e ajustá-la às vicissitudes dos tempos modernos, nos primórdios ao culto das celebridades, e à imagem do precioso american dream. O cinema, como observou Edgar Morin (2005), não apenas contribuiu para a fabricação de um novo Olimpo, por meio do star system, mas também cedeu espaço para que figuras lendárias fora do âmbito cinematográfico ocupassem frames de seus altares, através dos dramas biográficos.

A cinebiografia ou biopic constitui, em um sentido amplo, um subgênero do drama, muito embora sua origem biográfica - individual ou coletiva - remeta a um discurso com maior proximidade da História que da Ficção e flerte com prerrogativas do cinema documental. Em vista dessa especial condição, sua ontologia está localizada em um espaço intermediário, razão pela qual seja uma produção também conhecida pelo nome de docudrama, embora não signifique que partilhe da mesma objetividade dos procedimentos 
produtivos de documentários. A cinebiografia trata-se do relato romanceado de uma história de vida. E, embora centrado em eventos históricos ou personalidades não ficcionais, o roteiro possui licença dramática para representar ações sob um ponto de vista bastante autoral, isto é, como e $o$ que poderia ter acontecido pode ser bastante flexíveis.

Aplicando às cinebiografias conceitos do roteirista Doc Comparato (2009, p. 315-316) acerca dos graus de adaptação, quatro distinções principais podem ser circunscritas: "adaptação propriamente dita", no qual haveria alto grau de fidelidade aos fatos e às personalidades, contudo, com base em um recorte incisivo do montante literário para a passagem para o universo dramático audiovisual; "baseado em”, espécie de adaptação em segundo grau que permite ligeiro distanciamento do original, permitindo situações inventadas ou modificadas; "inspirado em", possibilidade narrativa em que o recorte do roteirista implica o ordenamento do personagem sob uma nova estrutura narrativa, tornando-se mais fiel à personalidade que aos fatos; e "recriação", variante de adaptação que consiste na manutenção da trajetória de vida, mas no deslocamento livre da personalidade/personagem no tempo e no espaço.

Camille Claudel (Camille Claudel, Bruno Nuytten, 1988) enquadrar-se-ia na primeira condição, por tratar-se de um drama biográfico adaptado do livro de Reine-Marie Paris sobre a escultora do título; Uma mente brilhante (A beautiful mind, Ron Howard, 2011), embora apoiado no livro homônimo de Sylvia Nasar, precisou criar personagens e situações para representar dramaticamente na tela a doença esquizofrênica do matemático John Nash; no filme sobre a fotógrafa Diane Arbus, A Pele (Fur: an imaginary portrait of Diane Arbus, Steven Shainberg, 2006), há uma reordenamento da biografada que a insere em um "retrato imaginário" cuja linha narrativa é ser um personagem da própria obra fotográfica, proporcionando ao espectador uma história “inspirada em”; Já o filme Não estou lá (I'm not there, Todd Haynes, 2007) faz Bob Dylan transitar por corpos de diferentes raças, gêneros e idades, criando um espaço-tempo indefinido ou mesmo mágico, de modo a jogar com a complexidade identitárias do músico e aproximando-se enormemente da ideia de recriação biográfica.

Ao contrário do que possa parecer, a adaptação biográfica no cinema é passível de muitos questionamentos porque se trata de um processo coletivo bastante complexo, observação que não pretende invalidar a categorização acima e, sim, relativizar sua acurácia na distinção dos objetos artísticos. Este trabalho se deterá apenas no produto final - a 
cinebiografia - e no modo como a memória contemporânea reverbera novas práticas de representar o biografado.

\section{Memória da fama infame}

A ficção happy end transposta para o mundo real não demorou a revelar suas falhas. Com o crash do star system, em declínio desde o fim da década de 1950, e sintomaticamente marcado pela morte trágica de James Dean, em 1955, e pelo suicídio de Marylin Monroe, sete anos mais tarde, a representação da memória mudou sensivelmente. O fim sacrificial da atriz, figurado no imaginário coletivo como o mito da beleza interrompida, contribuiu para que a mídia desconstruísse a ilusão de felicidade proposta por Hollywood e revelasse a parte maldita por trás da vida das celebridades - suas incoerências, fracassos, dramas e infelicidades. A vida pessoal, então, tornou-se novamente independente da fictícia personagem pública. Apesar de semelhante quebra no imaginário ter abalado a estrutura ficcional das trajetórias de sucesso, a fábula capitalista do "ser alguém", proposta pelo star system, não foi apagada. Com ela, a fantasia ingênua do sucesso e da felicidade continua até hoje a impulsionar os cidadãos anônimos em busca do reconhecimento público, da riqueza, da beleza e do glamour, como provam programas televisivos como os do tipo Big Brother, Ídolos, Fama e similares.

Com a desconstrução do mito de felicidade hollywoodiano, os ídolos cinematográficos, até aquele tempo vistos como deidades ou entidades etéreas, deixaram de ter sua vida representada como um conjunto particular de glórias e triunfos para assumir uma versão mais humanizada. Na nova ficção memorialista, as celebridades são suscetíveis de experimentar erros e acertos como qualquer um. Essa prerrogativa pode ser expressa pelo princípio de que, no universo hedonista do consumo, do coração e da morte, todos os sujeitos são iguais diante das necessidades e dos destinos. Tal condição colabora para que a poética biográfica contemporânea idealize e demonize mais os sujeitos biografados.

O jornalista Felipe Pena (2004) defende que o surgimento da midiagrafia - a biografia em tempo real das redações jornalísticas, especialmente do jornalismo tabloide - é sintomático de uma cultura centrada no espetáculo, ao que poderíamos acrescentar, de um tempo no qual se dá, de modo irreversível, a transformação da "parte maldita" das celebridades em mercadoria e em informação. Edgar Morin (2003, p. 110) já apontava que 
durante o star system um ramo do jornalismo havia se especializado em difundir a "vida dos sonhos" das estrelas de cinema, mas o sociólogo não deixou de observar o quanto os fracassos pessoais delas se tornaram também uma forma disputada de comércio. As tragédias e os sofrimentos em torno das vidas de Marilyn Monroe e de Brigitte Bardot, por exemplo, por causarem enorme frisson entre o público, ao contrário do esperado, tornaram seu espaço privado em algo mais dramático e, por isso mesmo, mais interessante, polêmico e vendável.

A radicalização contemporânea desse efeito é a equivalência entre fama e infâmia, por meio da qual se reifica até mesmo os feitos negativos do sujeito para que, a qualquer custo, não tenha seu nome esquecido em meio a uma memória pública cada vez mais volátil e diversificada. Para alguns, a matéria biográfica negativa, na atualidade, tornou-se inclusive uma poderosa estratégia de marketing (o que dizer da vida turbulenta de Amy Winehouse, Paris Hilton, Lindsay Lohan e tantos outros artistas?) e, para outros, até mesmo um objeto rentável, como prova a existência dos paparazzi e seus lucrativos registros fotográficos (merece atenção o polêmico caso que os tornou culpados pela morte da princesa Diana).

Se em outros tempos os parentes eram, como diz a jornalista Janet Malcolm (1995, p. 18), os "os inimigos naturais do biógrafo", "as tribos hostis" que procuravam preservar a melhor imagem possível dos seus, fazendo valer o crime de calúnia contra os mortos, a postura contemporânea parece estar sendo outra. Como as biografias têm sido produzidas enquanto os artistas ainda estão na crista da onda, qualquer fala enviesada é logo remendada por uma biografia, disposta a contar toda a verdade, ou outra variante de verdade.

É no tempo pós-moderno das múltiplas verdades/mentiras que surgiram livrosdesabafo como o de Christopher Ciccone, ao publicar Minha vida com minha irmã Madonna (2008), ou mesmo de Lynne Spears com Britney Spears - a história por trás do sucesso, publicação que ainda tem como chamativo subtítulo A mãe de Britney conta tudo sobre a carreira da filha (2009). São memórias debruçadas em um valor de autenticidade e apoiadas na ideia de que não há pessoas mais autorizadas - e com autoridade/propriedade - a falar do que, por exemplo, o próprio irmão ou a própria mãe. Ou, como o mercado parece indicar, nada melhor que um familiar para rasurar a imagem [i]maculada de uma personalidade com detalhes escusos de sua vida privada.

Por isso, o fenômeno de consumo de biografias e cinebiografias tem representado um importante filão no mercado literário e audiovisual, sobretudo quando estes discursos estão debruçados em personalidades marcadas por catástrofes pessoais. Apesar de parecer recente, foi por volta da década de 1950, depois da queda dos muros de contenção, da fachada da 
frente da "ficção da felicidade" de Hollywood, o público desenvolveu um interesse quase pornográfico pela experiência privada, curiosidade potencializada quando envolta por alguma viravolta de caráter escandaloso, passional ou destrutivo. O voyeurismo público para os conflitos da vida íntima era uma prática latente desde o star system e, com o surgimento da cultura do espetáculo e da vigiada e atual casa de vidro, encontra um espaço propício para fecundação e crescimento. Assim, o cinema, ao transformar personalidades públicas em personagens de uma narrativa, tendenciosamente reafirma clichês romanescos nos quais o amor sobressai como fermentação mítica em meio ao recorte dos choques e as perturbações de uma história pública.

O dramaturgo e roteirista David Mamet (2001, p. 33), criando um paralelo entre as ficções biográficas e as narrativas ficcionais, sugere que para o espectador é mais fácil identificar-se com a busca por um documento secreto do que com uma cientista, como Marie Curie, procurando identificar e compreender o elemento químico rádio. Sendo assim, "para serem eficazes, os elementos dramáticos têm de ter precedência - e acabarão por tê-la - sobre quaisquer fatos biográficos "reais", razão por que os diretores de biografias dramatizadas sempre recorrem às licenças dramáticas da ficção. O caso de artistas e escritores é ainda mais particular já que são personalidades de um universo laboral interior, lento e pouco afeito à representação plena no meio audiovisual. Por isso, para Mamet, pouco importaria ao espectador saber sobre a descoberta do rádio, o que importa no cinema é descobrir como, na cinebiografia de Marie Curie, o cão da heroína morreu.

Para dar estrutura dramática às cinebiografias, apresentando personalidades na forma de personagens, não raras vezes, os roteiristas se valem de um panorama compacto que vai desde o processo de formação do artista até o seu declínio. Dentre os elementos mais frequentes de tal prescrição pode-se destacar: a fábula da infância pobre e das muitas privações sofridas antes da consagração mundial; a noção do talento como característica inata; a aura feliz de superação das barreiras com o esforço profissional e o reconhecimento advindo dele; a ênfase no evento transformador do destino social; a personalidade dividida entre comportamentos distintos no espaço privado e no espaço público; a lenda da ascensão meteórica; a frequente nostalgia da infância e de um modo de vida comum; a narrativa romântica do encontro com o amor; a fragilidade do corpo, da paixão e da fama; as circunstâncias sombrias da derrocada; o mito do artista morto em plena atividade, no auge da carreira. Outras micronarrativas ainda poderiam ser acrescentadas a esse conjunto, mas a amostragem já nos aponta o quanto interessam ao público os efeitos dos feitos. 
A licença dramática, por essa razão, constitui procedimento legítimo no processo de filmagem de roteiros biográficos. Por meio de tal expediente, a teatralização da vida de uma personalidade recebe camadas de ficção responsáveis por construir uma "força-personagem" estilizadora e esquematizadora da vida de um sujeito. A ficcionalização narrativa, nesse sentido, ainda que apoiada na simplificação de uma complexa identidade, destacaria os traços mistificadores do sujeito biografado, o que o torna uma figura de papel como um personagem de romance.

Um traço problemático a ser apontado nas biopics, devido à facilidade de circulação e o consumo de uma obra audiovisual, em contraste com uma obra escrita, o cinema contribui para a formatação coletiva de uma imagem biográfica. Construída com base em uma forma aceitável - a narrativa cronológica -, segundo uma força transformadora - a tradução da personalidade em personagem - e por meio de graus de fabulação - parte do processo de adaptação de uma narrativa literária para o meio audiovisual -, o filme procura autorizar-se como história autêntica ou acaba sendo autorizado pelo espectador ingênuo como tal. Ou seja, o cinema, mais que as biografias de papel, em razão de sua natureza formativa na contemporânea civilização da imagem, contribui enormemente para perpetuar e difundir a ilusão biográfica.

\section{Duas cinebiografias contemporâneas}

Possivelmente a questão conceitual da memória - o que é, como registrar, qual a natureza do registro - tenha se tornado um dos objetos teóricos mais discutidos nos últimos tempos. Além do debate acerca das variações da verdade nas memórias particulares de cada sujeito, bem como dos graus de efabulação de cada relato mnemônico, a noção positivista do discurso tem sido igualmente revisitada e colocada sob escrutínio, sobretudo em um tempo no qual é possível a montagem espaço-temporal por conta das tecnologias disponíveis, dos satélites às webcams em rede.

Aparentemente a modernidade e seu aparato tecnológico têm contribuído enormemente para tornar o século XXI uma era propícia aos registros e à preservação. Afora a vantagem técnica e política, também podemos dizer que esta é uma era de extremos memorialistas. O museu, por exemplo, deixou de ser um espaço para a conservação de um tipo de arte de caráter histórico, de valor artístico consagrado, imbuída de peças com um hic 
et nunc. Há os museus de arte moderna, com peças já nascidas dentro dos próprios museus; há museus virtuais com plataformas digitais de visitação; há museus do lixo ao luxo. Tal contexto dá a entender que a sociedade contemporânea parece estar se tornando uma sociedade do colecionismo - acumulando tudo. Vivemos um tempo de museificação de todos os objetos e de transformação dos eventos cotidianos em memória hard disk.

Nesse sentido, a popularização das máquinas fotográficas digitais, dos smartphones e das redes sociais também constitui um traço importante desta nova realidade. A experiência, seu caráter de memória permanente, tem sido substituída pela vivência e seu enlace à noção de memória temporária, isto é: somos tentados a registrar em imagens ou em palavras o que comemos, onde estamos, com quem estamos e o que estamos fazendo. A memória, ou pelo menos uma parte dela, está se transformando em informação, em algo mais relacionado ao presente que ao passado, o que a faz perder seu caráter épico e sua relação com a retenção dos afetos. E pior: tornando-se cada vez mais indistinta em relação à ficção. Quanto a isso, um olhar sobre duas produções cinematográficas pode ser bastante esclarecedor.

Em 2002, no mesmo ano que o rapper Eminem lançou seu quarto álbum, a indústria cinematográfica produziu a cinebiografia 8 Mile - Rua das ilusões, relato do início da carreira musical do artista, ocorrida seis anos antes do filme. A narrativa cinematográfica, ecoando o princípio da midiagrafia, representa sua história primitiva, isto é, a passagem do caótico universo familiar e do anonimato à entrada no circuito do hip hop americano. Os elementos compositivos tradicionais estão presentes - a dramatização do processo criativo, os vaticínios da fama, os conflitos com um lar acidentado, o encontro com o amor, a crença no próprio talento. O roteiro, no entanto, declara-se apenas baseado na história de Eminem, exigindo-se como um drama semibiográfico (caberia aqui mais o conceito de "inspirado em", conforme apresentado anteriormente). Do latim, o prefixo semi, além de apontar para as ideias de 'meio, metade'; está também revestido de noções de 'quase' e 'um tanto'. Como avaliar, então, um discurso intermediário, semirreal, semibiográfico?

No filme, Eminem interpreta a si mesmo, ou melhor, interpreta um tipo de alter ego chamado Jimmy "B-Rabbit" Smith, um jovem cantor de rap, vivendo com a mãe alcóolatra e a irmã pequena em um trailer, e lutando para destacar-se nas batalhas de hip hop, nas quais prevalecem os negros. Rabbit, apelido pelo qual é chamado, tem uma origem mais humilhante do que aquela apontada pelos amigos, de ser rápido e gostar de sexo: sua mãe o havia chamado assim porque quando criança era orelhudo, dentuço e branquelo, como um coelho. 
O meio-termo do roteiro parece fundar de maneira bastante sutil o que constituirá, mais tarde e na vida real, uma série de ataques do rapper, por meio de suas canções, à própria mãe e às humilhações que teria sofrido ao viver com ela. É até interessante perguntar-se se ao interpretar sua contraparte ficcional Eminem, cujo verdadeiro nome é Marshall Matters, não estaria realizando uma espécie de psicodrama ao dramatizar cenas imaginadas de conflitos bastante reais.

Muito embora a história tenha sido bastante romantizada, o Eminem fora do cinema levou às últimas consequências suas denúncias em relação à sua mãe, acusando-a nas suas letras, de um modo bastante ofensivo, de ser uma viciada em drogas e uma negligente em relação à família. Algo bastante diferente dos pequenos erros que foram expressos na tela. Foi por conta das agressões reais que Debbie Matters, sua mãe, lançou o livro de memórias $M y$ son Marshall, my son Eminem, procurando contar "corretamente" sua relação com o filho. O universo de desafetos do rapper, no entanto, não se limita apenas à mãe, estendendo-se por muitas figuras públicas e celebridades pop, o que já lhe rendeu inúmeros processos, inclusive da progenitora. Como a própria Debbie declara no livro, o filho precisava dos xingamentos à mãe nas suas canções porque era o que fazia a plateia vibrar. A afirmação é bastante representativa desse tempo no qual a fama está estreitamente relacionada à infâmia, lógica por meio da qual os parentes têm sido os primeiros a jogar sujeira no ventilador ao revelar em biografias não autorizadas a vida íntima de seus familiares. Se for assim, nada melhor que o próprio Eminem para interpretar as suas meias memórias no cinema.

O gênero biográfico, dado esse contexto, tem perdido sensivelmente sua relação com a história do sujeito no tempo, no sentido de um pretérito perfeito e de um ciclo encerrado, para manter conexão mais estreita com o presente e o futuro do presente. Em outras palavras: as biografias estão deixando de ser um gênero dos mortos. São os vivos, enquanto ainda estão vivos, a matéria de memória contemporânea, resultado expressivo da presença da mídia e dos gêneros factuais, como a entrevista e o documentário no fazer biográfico.

Quando um documentário e biografias sobre Justin Bieber chegaram ao mercado, por exemplo, provocaram certo estranhamento principalmente por parte daqueles que não são fãs do jovem cantor. Em vista de uma premissa do saber popular também muito associada ao fazer biográfico, aquela que vincula experiência à sapiência, muitas pessoas questionavam: afinal, o que um garoto de apenas 16 anos tem para contar? Parafraseando Walter Benjamin (1994, p. 198), poderíamos dizer que o narrador biográfico é percebido tacitamente como 
alguém que vem de longe - um viajante do tempo - por isso está autorizado a dizer. Mas, neste caso, de qual autoridade estaríamos falando?

O documentário Justin Bieber: never say never (2011) embarca na lógica positivista do "esteve na origem desde sempre", ou seja, pontua uma imagem de predestinação e reafirma a mitologia do talento excepcional - Justin desde cedo mostrara talento para instrumentos musicais e para o canto, habilidade que apenas se desenvolveu com o passar dos anos e tornou-se questão de tempo - e de oportunidade - para ser reconhecido. Em entrevista à MTV, o cantor pop afirmou que, com o documentário, ele quer que "todos saibam que muita gente sempre vai estar pronta para fazer você desistir dos seus sonhos, mas que cabe a você não ficar desencorajado. O céu é o limite, sempre temos que nos lembrar disso!’. Como surge na fala de uma fã no próprio documentário, ver o que um garoto que saiu do interior do Canadá, foi descoberto por meio dos seus vídeos postados no Youtube, tornou-se para o mundo, é algo que lhe dá esperança. Nesse sentido o documentário não faz mais que reforçar uma narrativa muito presente em roteiros de filmes musicais, do artista que sai da cidade pequena, tenta a sorte na grande cidade, enfrenta problemas pessoais e profissionais e, por fim, encontra seu lugar ao sol no hall da fama. É o retorno da ficção de felicidade do star system, sob uma roupagem ainda mais consumista.

No caso de Justin Bieber, a pressa por um documentário, quem sabe por uma cinebiografia, esteja relacionando também com um vaticínio de Andy Warhol: "Ninguém mais será famoso por mais de 15 minutos", sobretudo se pensarmos em uma sociedade de consumo que nos obriga a uma constante renovação dos produtos culturais, fazendo com que tudo seja produzido, transmitido, reproduzido, copiado e substituído em uma velocidade nunca antes imaginada. Seguindo essa lógica da efemeridade, é de se esperar que as memórias de um astro mirim - que talvez não consiga superar a adolescência com a mesma força no meio musical - sejam lançadas quase de modo imediato, seja na forma de memóriainformação, seja ao modo de memória-ficção. E, também, talvez seja sintomático de um tempo no qual a memória está cada vez mais atrelada às perguntas do Twitter, "O que está acontecendo?", ou do Facebook, "No que você está pensando?”. Com apenas 140 caracteres e alguns posts podemos dizer que a memória, de alguma forma, perdeu seu fôlego e não temos mais que ir em busca do tempo perdido. O tempo de resgate é o agora. 


\section{Referências}

BENJAMIN, Walter. O narrador - considerações sobre a obra de Nikolai Leskov. In: Magia e técnica, arte e política: ensaios sobre literatura e história da cultura. Tradução de Sérgio Paulo Rouanet. 7.ed. São Paulo: Brasiliense, 1994. p. 197- 221.

BOURDIEU, Pierre. A ilusão biográfica. In: FERREIRA, Marieta de Moraes; AMADO, Janaína (orgs.). Usos e abusos da história oral. 8.ed. Rio de Janeiro: Editora FGV, 2006. p. $183-191$.

CICCONE, Christopher. A vida com minha irmã Madonna. Tradução de Carolina Caires Coelho. São Paulo: Planeta do Brasil, 2008.

8 MILE - RUA DAS ILUSÕES. Direção de Curtis Hanson. Roteiro de Scott Silver. Baueri, SP: Universal Pictures do Brasil, 2002. 1 DVD: 110 min., NTSC, son., color.

FIELD, Syd. Manual do roteiro - os fundamentos do texto cinematográfico. Tradução de Alvaro Ramos. Rio de Janeiro: Objetiva, 2001.

JUSTIN BIEBER: NEVER SAY NEVER. Direção de Jon Chu. Baueri, SP: Paramount do Brasil, 2011. 1 DVD: 105 min., NTSC, son., color.

MALCOLM, Janet. A mulher calada: Sylvia Plath, Ted Hughes e os limites da biografia. Tradução de Sérgio Flaksman. São Paulo: Companhia das Letras, 1995.

MAMET, David. Três usos da faca: sobre a natureza e a finalidade do drama. Tradução de Paulo Reis. Rio de Janeiro: Civilização Brasileira, 2001.

MORIN, Edgar. Cultura de massas no século XX: Neurose. Tradução de Mauro Ribeiro Sardinha. 9.ed. Rio de Janeiro: Forense Universitária, 2005.

Cultura de massas no século XX: Necrose. vol. 2. Tradução de Agenor Soares Santos. 3. ed. Rio de Janeiro: Forense Universitária, 2003.

PENA, Felipe. Teoria da biografia sem fim. Rio de Janeiro: Mauad, 2004.

SPEARS, Lynne. Britney Spears: a história por trás do sucesso: a mãe de Britney conta tudo sobre a carreira da filha. Tradução de Bárbara Coutinho. Rio de Janeiro: Thomas Nelson Brasil, 2009.

[Texto apresentado durante o evento em comemoração aos 20 anos da Revista: Anuário de Literatura, memórias em perspectiva, ocorrido em 28 de novembro de 2012]

\section{Reflections on autobiographical memory in the contemporary audiovisual medium}

Abstract: The biographical discourse follows a traditional positivist model, focused on relations of cause and effect, and composes a chronological logic to present a life story. In the last decades, scholars have questioned this crystallized form and have offered new 
possibilities for the writing of the biographies. The audiovisual product, object of interest of this work, despite certain advantages over paper model, still produces screenplays in which the slices of life of an individual are an ordered succession of events in time. The purpose of this article is therefore reflect on how memory is present in the biographical films and what kind of contemporary modifications have been introduced into the trivial model so as to remove the mythical aspect that involves the biographees.

Keywords: Biography. Biopic. Contemporaneity. Memory. Representation.

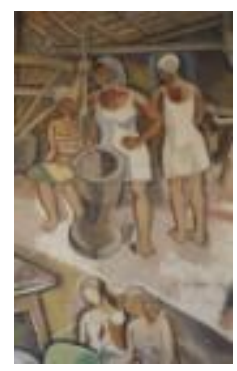

